\title{
Exosomes Derived From M2b Macrophages Attenuate DSS-Induced Colitis
}

OPEN ACCESS

Edited by:

Mats Bemark,

University of Gothenburg, Sweden

Reviewed by:

Dapeng Chen

Dalian Medical University, China Alan C. Moss,

Harvard Medical School, United States

${ }^{*}$ Correspondence: Dongya Yuan dy62@163.com

Zhongdao Wu

wuzhongdao@mail.sysu.edu.cn

Xi Sun

sunxi2@mail.sysu.edu.cn

tThese authors have contributed equally to this work and share first authorship

Specialty section:

This article was submitted to

Mucosal Immunity,

a section of the journal

Frontiers in Immunology

Received: 04 June 2019 Accepted: 17 September 2019

Published: 16 October 2019

Citation:

Yang R, Liao Y, Wang L, He P, Hu Y,

Yuan D, Wu Z and Sun X (2019)

Exosomes Derived From M2b

Macrophages Attenuate DSS-Induced Colitis. Front. Immunol. 10:2346. doi: 10.3389/fimmu.2019.02346

\author{
Ruibing Yang ${ }^{1,5+}$, Yao Liao ${ }^{2,3,4 t}$, Lifu Wang ${ }^{2,3,4 t}$, Ping He ${ }^{1,5}$, Yuanjia $\mathrm{Hu}^{6}$, Dongya Yuan ${ }^{1,5 *}$, \\ Zhongdao $\mathrm{Wu}^{2,3,4 *}$ and $\mathrm{Xi} \mathrm{Sun}^{2,3,4 *}$
}

1 Medical Department of Xizang Minzu University, Xianyang, China, ${ }^{2}$ Department of Parasitology of Zhongshan School of Medicine, Sun Yat-sen University, Guangzhou, China, ${ }^{3}$ Key Laboratory of Tropical Disease Control, Ministry of Education, Sun Yat-sen University, Guangzhou, China, ${ }^{4}$ Provincial Engineering Technology Research Center for Biological Vector Control, Guangzhou, China, ${ }^{5}$ Key Laboratory for Basic Research in Life Sciences, Institutions of Higher Learning, Xianyang, China, ${ }^{6}$ State Key Laboratory of Quality Research in Chinese Medicine, Institute of Chinese Medical Sciences, University of Macau, Macau, China

Macrophages are commonly classified as M1 macrophages or M2 macrophages. The M2 macrophages are further sub-categorized into M2a, M2b, M2c, and M2d subtypes. The M2a, M2b, and M2c subtypes play roles in anti-inflammatory activity, tissue remodeling, type $2 \mathrm{~T}$ helper cell (Th2) activation, and immunoregulation. Previous studies have shown that macrophage exosomes can affect some disease processes. Exosomes are 30-150-nm lipid bilayer membrane vesicles derived from most living cells, with important biological functions. The role of exosomes in preventing the development of autoimmune diseases, including inflammatory bowel disease (IBD), has evoked increasing interest. Here, we analyze the roles of exosomes derived from $\mathrm{M} 2 \mathrm{a}$, M2b, and M2c macrophage phenotypes in dextran sulfate sodium (DSS)-induced colitis. Exosomes were isolated from the supernatant of different types of macrophages and identified via transmission electron microscopy (TEM), western blotting, and NanoSight. The results showed that M2b macrophage exosomes significantly attenuated the severity of DSS-induced colitis in mice. The number of regulatory $T$ (Treg) cells in the spleens of mice with colitis and levels of IL-4 both increased following treatment with M2b macrophage exosomes. In addition, key cytokines associated with colitis (IL-1 $\beta$, IL-6, and IL-17A) were significantly suppressed, following treatment with M2b macrophage exosomes. The M2b macrophage exosomes exerted protective effects on DSS-induced colitis, mainly mediated by the CC chemokine 1 (CCL1)/CCR8 axis. These findings provide a novel approach for the treatment of IBD.

Keywords: M2b macrophage, IL-1 $\beta$, exosomes, inflammatory bowel disease, CCL1/CCR8 axis

\section{INTRODUCTION}

Inflammatory bowel disease (IBD, including Crohn's disease and ulcerative colitis) is considered to be the result of chronic and remittent-relapsing intestinal inflammation and intestinal tract destruction (1). The condition represents a major global health care burden that affects millions of people worldwide, especially in Europe and North America, where its prevalence is the highest, and in Asia, where its incidence has been rising in recent years (2-4). 
The exact etiologies of IBD remain unknown. However, over the past few decades, the main factors responsible for Crohn's disease and ulcerative colitis are generally believed to include environmental changes, genetic make-up, abnormalities in the gut microbiota, and dysregulated immune responses $(5,6)$. Chronic inflammation is a dysregulated immune response; therefore, many investigations into the pathogenesis of IBD have been focused on immune abnormalities (5). Rectal bleeding, abdominal discomfort, diarrhea, and weight loss are the most common symptoms of IBD (7). Traditional treatments for IBD primarily consist of 5-aminosalicylic acid agents, steroids, and antimicrobials. However, these drugs have limitations and can induce adverse events. Within the past two decades, biological therapies have revolutionized the treatment of IBD, while demonstrating a higher efficacy and safety profile (8-10).

Macrophages are heterogeneous, circulate in the blood, or are concatenated in different organs and tissues, and constitute the first barrier against disease (11). The phenotype and functions of macrophages are regulated by the surrounding microenvironment (12). Macrophages are commonly classified into two distinct subsets based on the phenotype: (1) classically activated (M1) macrophages, which are typically induced by bacterial lipopolysaccharide (LPS) or type $1 \mathrm{~T}$ helper cell (Th1) cytokines, such as interferon (IFN)- $\gamma$ and tumor necrosis factor (TNF)- $\alpha$. The M1 macrophages secrete higher levels of proinflammatory cytokines, such as TNF- $\alpha$, interleukin (IL)- $1 \alpha$, IL-12, IL-23, IL-1 $\beta$, and IL-6. (2) Alternatively, activated (M2) macrophages are anti-inflammatory and polarized by type $2 \mathrm{~T}$ helper cell (Th2) cytokines (IL-4, IL-13, and IL-33). The M2 macrophages produce higher levels of the immunoregulatory cytokine, IL-10 (12, 13). Furthermore, depending on the activating stimulus, M2 macrophages can be classified as M2a, M2b, M2c, or M2d subtypes $(14,15)$. The M2a macrophages can be induced by IL- 4 and IL-13 and play a role in anti-inflammatory activity and tissue remodeling $(12,14,15)$. The M2b macrophages can be induced by stimulation with immune complexes, tolllike receptor (TLR) agonists, or IL-1 receptor ligands, and play a role in Th2 activation and immunoregulation $(12,14)$. The M2c subset of macrophages is induced by glucocorticoids, IL10 , or transforming growth factor (TGF)- $\beta$, and exhibits antiinflammatory activities by further releasing IL-10 and TGF- $\beta$ $(16,17)$. The M2d macrophage is induced by TLR agonists through the adenosine receptor and plays a role in angiogenesis and tumor progression (14).

Exosomes are 30-150-nm lipid bilayer membrane vesicles, which are derived from most living cells and released into the extracellular medium (18). They carry proteins, genes (mRNA, miRNA, and DNA), and lipids in vitro and in vivo, and have important biological functions (18). In recent years, the function and potential application of exosomes in IBD has evoked increasing interest. Previous studies have demonstrated that exosomes derived from dendritic cells (19), human umbilical cord mesenchymal stem cells (20), and granulocytic myeloidderived suppressor cells (21) can attenuate colitis. Because exosomes have less biohazardous potential and cytotoxicity, and are not easily degraded, they have more advantages over parental cells (22). Furthermore, because M2 macrophages are associated with anti-inflammatory and immunoregulatory activity, we hypothesized that the combined advantages of exosomes derived from various M2 macrophage phenotypes could be useful in the treatment of IBD. Moreover, the specific subtype of M2 macrophages with the best effects remains unknown.

In this study, M2 macrophage exosomes (M2a, M2b, and $\mathrm{M} 2 \mathrm{c}$ ) were isolated from the supernatant of different types of macrophages and the effects of these exosomes in IBD were evaluated. We found that M2 macrophage exosomes attenuated the severity of dextran sulfate sodium (DSS)-induced colitis, and exosomes derived from the M2b macrophages were more effective than those derived from M2a and M2c macrophages.

\section{MATERIALS AND METHODS}

\section{Animals and Ethics}

Male BALB/c mice, aged 6 weeks (weighing 18-20g), were purchased from the Experimental Animal Center of Guangdong. All animal experimental procedures were approved by the Animal Research Ethics Committee of Sun Yat-sen University and conformed to the Chinese National Institute of Health Guide for the Care and Use of Laboratory Animals.

\section{Macrophage Generation and Exosome Purification}

The femur and tibia of $\mathrm{BALB} / \mathrm{c}$ mice were removed, left in $75 \%$ ethanol for $5 \mathrm{~min}$, and then washed in Dulbecco's modified Eagle's medium (DMEM). Cells within the marrow were prepared in a single cell suspension and cultured in DMEM (GIBCO, Germany) with $10 \%(\mathrm{v} / \mathrm{v})$ fetal bovine serum, $100 \mathrm{U} / \mathrm{mL}$ of penicillin (Sigma, Germany), $100 \mu \mathrm{g} / \mathrm{mL}$ of streptomycin (Sigma, Germany), $1 \mathrm{mM}$ L-glutamine (Sigma, Germany), and recombinant murine macrophage colony-stimulating factor (MCSF) $(20 \mathrm{ng} / \mathrm{mL}$, PeproTech, USA). On the third and fifth days, half of the cell culture supernatant was discarded, and an equivalent volume of the medium was added. On the seventh day, bone marrow-derived macrophages (BMDMs) were harvested. The BMDMs were either stimulated with IL-13 (R\&D Systems, USA), IL-10 (R\&D Systems), or IL-1 $(\mathrm{R} \& \mathrm{D}$ Systems) or left untreated. The resulting culture supernatant and cells were harvested $24 \mathrm{~h}$ post-stimulation. Exosomes from the supernatant of the cell culture media were purified using an exosome isolation kit (Invitrogen, USA), according to the manufacturer's instructions.

\section{Electron Microscopy, NanoSight, and Western Blotting}

Exosomes were analyzed using negative-staining transmission electron microscopy (TEM). The exosomes were suspended in $2 \%$ glutaraldehyde and loaded onto copper grids, after which they were negatively stained with $3 \%(\mathrm{w} / \mathrm{v})$ aqueous phosphotungstic acid for $1 \mathrm{~min}$. The grids were examined using the FEI Tecnai G2 Spirit Twin transmission electron microscope. In addition, macrophage exosomes were analyzed using the NanoSight NS300 instrument (Malvern Instruments, UK).

The markers CD63, CD9, CD81, CCL1 of exosomes and CCL1, CCR8, and IL-4 of the mice colon were detected 
TABLE 1 | Scores of the disease activity index (DAl).

\begin{tabular}{lcll}
\hline Score & Body weight loss (\%) & Bleeding & Diarrhea \\
\hline 0 & $<2 \%$ & No blood in stool & Normal stool \\
1 & $\geq 2-<5 \%$ & Weak hemoccult in stool & Softer stool \\
2 & $\geq 5-<10 \%$ & Visible blood in stool & Unformed stool \\
3 & $\geq 10-<15 \%$ & Fresh rectal bleeding & Watery stool \\
4 & $\geq 15 \%$ & - & - \\
\hline
\end{tabular}

by western blotting. The standard sodium dodecyl sulfatepolyacrylamide gel electrophoresis (SDS-PAGE) procedure was followed, macrophage exosomes were lysed in a western blotting lysis buffer and separated using 10\% SDS-PAGE. Subsequently, proteins were electrophoretically transferred onto a polyvinylidene fluoride blotting membrane (GE Healthcare Life Sciences, UK), and then blocked using 5\% skimmed milk. The membranes were incubated with anti-mouse CD63, CD9, CD81, CCL1, CCR8, and IL-4 antibody (BD Biosciences, USA) overnight at $4^{\circ} \mathrm{C}$. Anti-mouse antibodies conjugated with horseradish peroxidase (HRP) (Jackson Immunoresearch Labs Inc., USA) were used as secondary antibodies. Membranes were visualized via an enhanced chemiluminescence (ECL) chemiluminescent detection system (Amersham, USA).

\section{Induction of Colitis and Treatment}

Acute colitis was induced by administering water with $3 \%$ (wt/vol) DSS (molecular mass 36-50 kDa; MP Biomedicals, Illkirch, France) to mice over 8 days (days 1-8). The control mice received regular drinking water. The cells of BMDMs were either unstimulated (M0) or stimulated with IL-13 (M2a), IL10 (M2c), or IL-1 $(\mathrm{M} 2 \mathrm{~b})$, and subsequently administered via intraperitoneal (i.p.) injection $\left(1 \times 10^{6}\right)$ on day 1 . Exosomes purified from different macrophage phenotypes (M0, M2a, M2b, and $\mathrm{M} 2 \mathrm{c}$ ) were administered via i.p. injection (50 mg per mouse) from days 1 to 8 . The same volume of the vehicle (phosphatebuffered saline, PBS) was administered to the control group via i.p. injection.

\section{Clinical Scoring of Disease}

Mice were observed daily during treatment. Any changes in body weight, or occurrence of diarrhea or bleeding were recorded. Bleeding was determined using the Hemoccult assay kit (Nanjing Jiancheng Bio-engineering Institute, China). The clinical disease score (disease activity index, DAI) was evaluated based on weight loss, diarrhea, and bleeding, as described by Sann et al. (Table 1) (23).

\section{Macroscopic Assessment and Histological Evaluation}

Mice were sacrificed on day 8 and their colons were resected. Colon length (an indirect marker of inflammation) was measured, and the macroscopic characteristics of colons were assessed by an independent observer blinded to the study. The macroscopic scores were assessed using the following
TABLE 2 | Assessment of macroscopic scores.

\begin{tabular}{ll}
\hline Score & The damage of colon \\
\hline 0 & No damage \\
1 & Hyperemia without ulcers \\
2 & Hyperemia and wall thickening without ulcers \\
3 & One ulceration site without wall thickening \\
4 & Two or more ulceration sites \\
5 & $0.5 \mathrm{~cm}$ extent of inflammation or major damage \\
$6-10$ & $1 \mathrm{~cm}$ extent of inflammation or severe damage \\
\hline
\end{tabular}

parameters: hyperemia, wall thickening, ulceration, and extent of inflammation and damage (Table 2) (24).

Colons were fixed overnight with $4 \%(\mathrm{w} / \mathrm{v})$ paraformaldehyde and then embedded in paraffin. Five-micrometer paraffinembedded colon sections were prepared and stained with hematoxylin and eosin ( $\mathrm{H} \& \mathrm{E}$ ). Histopathological scores were determined in a blinded fashion, according to the criteria described by Sann et al. (Table 3) (23). The histopathological scores of colonic lesions were assessed based on the extent of inflammation, neutrophilic and lympho-histiocytic infiltration, crypt damage, crypt abscess formation, sub-mucosal edema, loss of goblet cells, and reactive epithelial hyperplasia. The histopathological scores were determined by adding all scores of the aforementioned parameters.

\section{Flow Cytometry}

To determine the splenic regulatory $\mathrm{T}$ (Treg) subset levels, cells were isolated from the spleens of mice, washed in PBS, and stained with fluorochrome-conjugated antibodies against the cell surfaces of CD3e, CD4, and CD25 (BD Biosciences, USA). The antibodies were used at concentrations recommended by the manufacturers. Cells were then fixed and permeabilized using a fixation/permeabilization solution, according to the manufacturer's instructions, and stained with Foxp3. Images of all samples were acquired on a CytoFLEX S flow cytometer (Beckman Coulter, USA). The numbers of Tregs in the spleens were quantified and expressed as percentages of the $\mathrm{CD} 3 \mathrm{e}^{+} \mathrm{CD} 4{ }^{+} \mathrm{CD} 25^{+} \mathrm{Foxp}^{+}$cell population.

\section{RNA Extraction and Real-Time Polymerase Chain Reaction (PCR)}

Total RNA was isolated using the Trizol reagent (Invitrogen, USA). Furthermore, RNA was quantified by measuring the ratio of the absorbance at 260 and $280 \mathrm{~nm}$ using the NanoDrop ND2000 spectrophotometer (Thermo Scientific, USA). The RNA was converted to complementary DNA (cDNA) using a Thermo Scientific Revert Aid First Strand cDNA Synthesis Kit (Thermo Scientific, USA), according to the manufacturer's instructions. Furthermore, reverse transcription PCR was performed using SYBR Green QPCR Master Mix (TaKaRa, Japan). The reaction comprised an initial denaturation at $95^{\circ} \mathrm{C}$ for $30 \mathrm{~s}$, followed by amplification for 35 cycles at $95^{\circ} \mathrm{C}$ for $5 \mathrm{~s}$, and $60^{\circ} \mathrm{C}$ for $20 \mathrm{~s}$. The primers of IL-1 $\beta$, IL-6, IL-17A, CCL1, CCR8, IL-4, and 
TABLE 3 | Histopathological scores.

\begin{tabular}{|c|c|c|c|c|c|c|c|}
\hline Score & Inflammation & $\begin{array}{l}\text { Infiltration neutrophils + } \\
\text { lympho-histiocytes }\end{array}$ & Crypt damage & Crypt abscess & $\begin{array}{l}\text { Sub- } \\
\text { mucosal } \\
\text { edema }\end{array}$ & $\begin{array}{l}\text { Loss of } \\
\text { goblet cells }\end{array}$ & $\begin{array}{l}\text { Reactive epithelial } \\
\text { hyperplasia }\end{array}$ \\
\hline 0 & None & None & None & None & None & None & None \\
\hline 1 & Mucosa & Focal & Basal 1/3 & Focal & Focal & Focal & Focal \\
\hline 2 & Mucosa + submucosa & Multifocal & Basal 2/3 & Multifocal & Multifocal & Multifocal & Multifocal \\
\hline 3 & $\begin{array}{l}\text { Mucosa + submucosa } \\
+ \text { muscle layer }\end{array}$ & Diffuse & $\begin{array}{l}\text { Entire crypt } \\
\text { damage }\end{array}$ & - & Diffuse & Diffuse & Diffuse \\
\hline 4 & Transmural & - & $\begin{array}{l}\text { Crypt damage + } \\
\text { ulceration }\end{array}$ & - & - & - & - \\
\hline
\end{tabular}

TABLE 4 | Primers used for real-time PCR analysis.

\begin{tabular}{lll}
\hline Genes & Primer & Sequence $\left(\mathbf{5}^{\prime} \rightarrow \mathbf{3}^{\prime} \mathbf{)}\right.$ \\
\hline $\mathrm{IL}-1 \beta$ & Forward primer & CTCACAAGCAGAGCACAAGC \\
& Reverse primer & TCCAGCCCATACTTAGGAAGA \\
IL-6 & Forward primer & TAGTCCTCCTACCCCAATTCC \\
& Reverse primer & TTGGTCCTAGCCACTCCTTC \\
IL-17A & Forward primer & GCTCCAGAAGGCCCTCAGACT \\
& Reverse primer & CCAGCTTCCCTCCGCATTGA \\
CCL1 & Forward primer & GGATGTTGACAGCAAGAGCA \\
& Reverse primer & ACAGGAGGAGCCCATCTTTC \\
CCR8 & Forward primer & TGGTGCTCACCGTAGTCATT \\
& Reverse primer & TCCATCCAAGATGTGCAGGT \\
IL-4 & Forward primer & AACGAGGTCACAGGAGAAGG \\
& Reverse primer & CTGCAGCTCCATGAGAACAC \\
GAPDH & Forward primer & ACTCCACTCACGGCAAATC \\
& Reverse primer & TCTCCATGGTGGTGAAGACA \\
\hline
\end{tabular}

glyceraldehyde-3-phosphate dehydrogenase (GAPDH) are listed in Table 4.

\section{Ex vivo Fluorescence Imaging of Exosomes in the Colon}

Exosomes were stained with $\operatorname{DiR}\left(1,1^{\prime}\right.$-dioctadecyl-3,3,3',3'tetramethylindotricarbocyanine iodide), and then centrifuged at $120,000 \mathrm{~g}$ for $1.5 \mathrm{~h}$ at $4{ }^{\circ} \mathrm{C}$ in an Optima L-100xp tabletop ultracentrifuge (Beckman, USA) to wash the unstained DiR. Mice were injected with DiR labeled exosomes. Mice were then sacrificed $12 \mathrm{~h}$ later, their colons were resected, and fluorescence images were obtained using an in vivo imaging system (Maestro, USA).

\section{Immunohistochemistry}

Immunohistochemistry was performed to evaluate CCL1, CCR8, and IL-4 protein expression levels in the colon. The paraffin sections were deparaffinized and antigen retrieval was performed by irradiating the samples in a microwave. The sections were incubated with $3 \% \mathrm{H}_{2} \mathrm{O}_{2}$ to block endogenous peroxidase activity, after which they were blocked with $1 \%$ bovine serum albumin and incubated with anti-mouse CCL1, CCR8, and
IL-4 antibodies (1:100) overnight at $4^{\circ} \mathrm{C}$. The sections were then incubated with the secondary antibody. HRP activity was detected by 3, 3'diaminobenzidine (DAB). The sum of the integrated optical density (IOD) was analyzed using the ImagePro Plus 6.0 software.

\section{Statistical Analyses}

Data were expressed as mean \pm standard error of the mean (SEM). One-way analysis of variance (ANOVA), followed by the Dunnett's post hoc test were used to analyze the various groups. $P<0.05$ was considered statistically significant.

\section{RESULTS}

\section{Isolation and Identification of Macrophage Exosomes}

The BMDMs were cultured in vitro and treated with IL-13, IL-10, and IL-1 $\beta$ to induce the phenotypes of M2a, M2c, and $\mathrm{M} 2 \mathrm{~b}$, respectively, and M0 (untreated) was considered the control. After $24 \mathrm{~h}$, culture supernatants were collected, and exosomes were extracted from the supernatants using extraction kits (from cell culture media), according to the manufacturer's instructions. The purity, quality, and morphology of the exosomes were analyzed using negativestaining TEM. Isolated macrophage exosomes were observed to have closed round vesicles with a typical diameter of $30-150 \mathrm{~nm}$ (Figure 1A). Furthermore, the expression of exosome markers CD63, CD9, and CD81 was detected by western blotting (Figure 1B). In addition, NanoSight was used to investigate the distribution profile of macrophage exosomes and revealed a peak of $72 \mathrm{~nm}$ (Figure 1C). These data indicate that the exosomes were successfully isolated from the culture supernatants.

\section{M2 Macrophage Exosomes Attenuate the Clinical Scores of Mice With DSS-Induced Colitis}

To assess the effect of M2 macrophage exosomes on the development of colitis, the DSS-induced colitis model was established. The following groups of mice were used: water + PBS; DSS + PBS; DSS + M0-cell; DSS + IL-13-cell; DSS + 
A

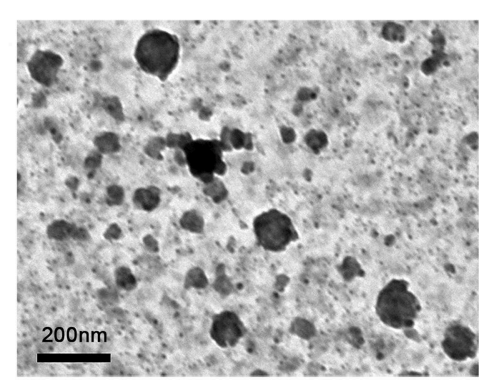

C ${ }^{7}$

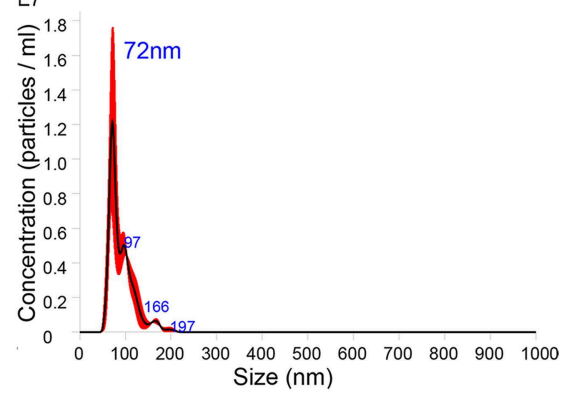

B
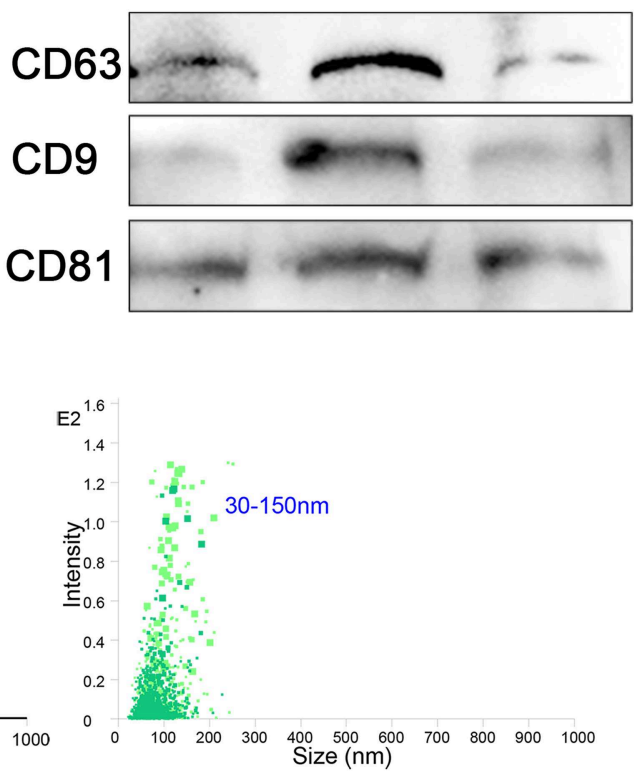

FIGURE 1 | Exosomes were purified from the supernatant of macrophages. (A) Exosomes were analyzed by negative-staining transmission electron microscopy (TEM). (B) Exosome specific markers CD63, CD9, and CD81 were detected by western blotting. (C) The size distribution profile of the exosomes was analyzed by NanoSight.

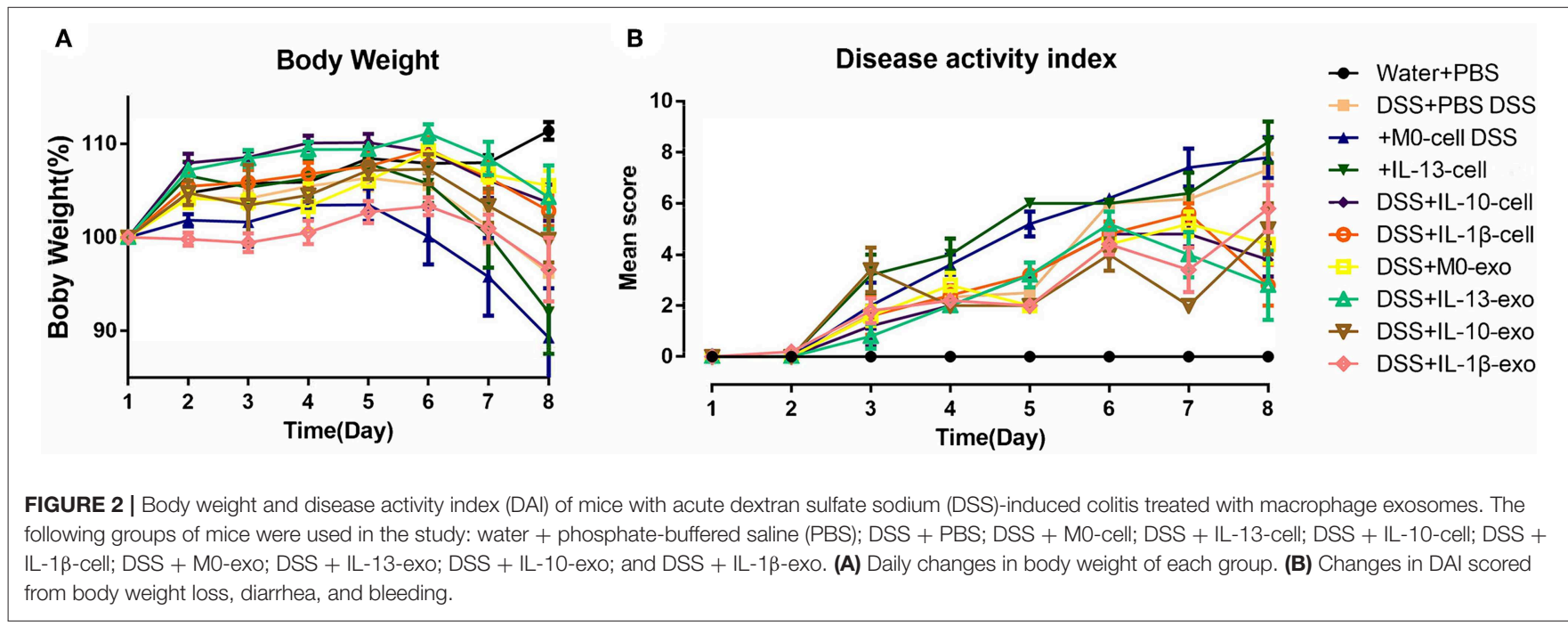

IL-10-cell; DSS + IL-1 $\beta$-cell; DSS + M0-exo; DSS + IL-13exo; DSS + IL-10-exo; and DSS + IL-1 $\beta$-exo. The DSS + M0cell; DSS + IL-13-cell; DSS + IL-10-cell; and DSS + IL-1 $\beta$ cell groups were injected (i.p.) with cells $\left(1 \times 10^{6}\right)$ of BMDMs that were either unstimulated (M0), or stimulated with IL-13 (M2a), IL-10 (M2c), or IL-1 $\beta$ (M2b) on day 1 . The DSS + M0-exo; DSS + IL-13-exo; DSS + IL-10-exo; and DSS + IL$1 \beta$-exo groups were injected (i.p.) with exosomes purified from macrophage phenotypes of M0 (unstimulated); M2a (stimulated with IL-13); M2b (stimulated with IL-1 $\beta$ ); and M2c (stimulated with IL-10) from days 1 to 8 . The water + PBS and DSS
+ PBS groups were injected (i.p.) with a similar volume of vehicle (PBS).

The clinical disease score was evaluated based on weight loss, diarrhea, and bleeding. As shown in Figure 2A, mice of the DSS + PBS group lost weight over time, and weight loss in mice with colitis that were treated with M2 macrophages (DSS + IL-13-cell; DSS + IL-10-cell; and DSS + IL- $1 \beta$-cell groups) was alleviated. In addition, weight loss in mice with colitis that were treated with M2 macrophage exosomes (DSS + M0-exo; DSS + IL-13exo; DSS + IL-10-exo; and DSS + IL-1 $\beta$-exo) was also alleviated. The DSS treatment caused severe diarrhea and bleeding in mice 


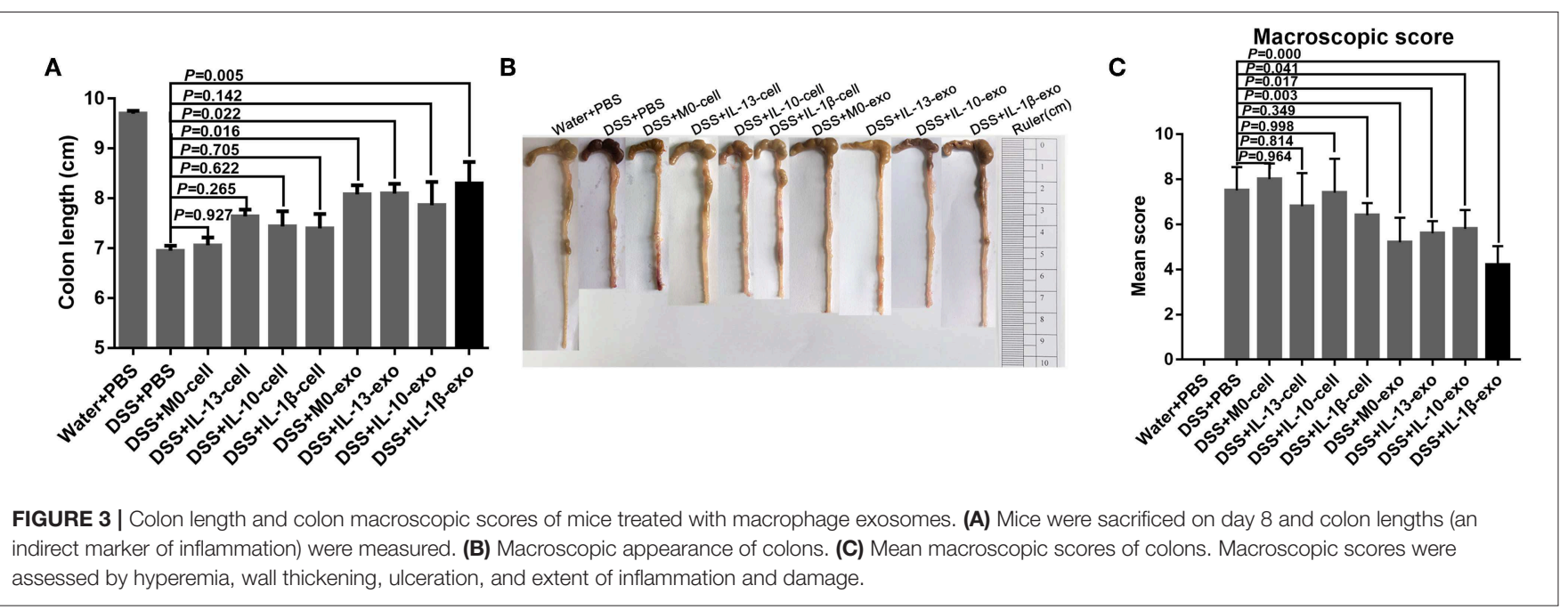

TABLE 5 | Values of the evaluation indexes.

\begin{tabular}{|c|c|c|c|c|c|c|}
\hline Group & DAl on day 8 (mean) & $\begin{array}{l}\text { Colon length (cm) } \\
\text { (mean) }\end{array}$ & $\begin{array}{l}\text { Macroscopic scores } \\
\text { (mean) }\end{array}$ & $\begin{array}{l}\text { Histopathological } \\
\text { score (mean) }\end{array}$ & $\begin{array}{c}\text { Treg subset levels } \\
\text { (mean) }\end{array}$ & $n$ \\
\hline Water + PBS & 0.0 & 9.7 & 0.0 & 0.0 & 10.3 & 6 \\
\hline$D S S+P B S$ & 7.3 & 6.9 & 7.5 & 12.5 & 9.3 & 6 \\
\hline DSS + MO-cell & 7.8 & 7.1 & 8.0 & 12.0 & 9.6 & 6 \\
\hline DSS + IL-13-cell & 2.8 & 7.6 & 6.8 & 14.4 & 10.1 & 6 \\
\hline DSS + IL-10-cell & 8.4 & 7.4 & 7.4 & 10.2 & 10.0 & 6 \\
\hline DSS + IL-1 $\beta$-cell & 3.8 & 7.4 & 6.4 & 5.8 & 8.3 & 6 \\
\hline DSS + MO-exo & 4.4 & 8.1 & 5.2 & 14.4 & 8.8 & 6 \\
\hline DSS + IL-13-exo & 5.0 & 8.1 & 5.6 & 11.0 & 10.7 & 6 \\
\hline DSS + IL-10-exo & 2.8 & 7.9 & 5.8 & 10.4 & 13.5 & 6 \\
\hline DSS + IL-1 $\beta$-exo & 5.8 & 8.3 & 4.2 & 4.0 & 12.7 & 6 \\
\hline
\end{tabular}

with colitis. Moreover, M2b and M2c macrophages, and M2a, $\mathrm{M} 2 \mathrm{~b}$, and M2c macrophage exosomes alleviated the severity of diarrhea and bleeding. The effects of M2 macrophage exosomes were superior to those of M2 macrophages. The DAI of mice with colitis that were treated with M2 macrophage exosomes was lower than the DAI of those treated with PBS, M0 macrophages, or M2 macrophages (Figure 2B).

\section{M2b Macrophage Exosomes Ameliorate Reduction of the Colon Length and Macroscopic Scores in DSS-Induced Colitis}

Colon length can be significantly reduced by DSS in the mouse model. To evaluate the therapeutic potential of M2 macrophage exosomes in mice with DSS-induced colitis, the colon length was evaluated. The results showed that the colons of mice with colitis, which were treated with M2b macrophage exosomes were longer than those of other groups of mice with colitis (Figures 3A,B, Table 5). The macroscopic scores were assessed by hyperemia, wall thickening, ulceration, and the extent of inflammation and damage. The mean macroscopic scores of mice with colitis that were treated with M2b macrophage exosomes were lower than those of other groups of mice with colitis (Figure 3C, Table 5). These results demonstrate that M2b macrophage exosomes more effectively ameliorate the reduction of colon length and reduce macroscopic scores in mice with DSS-induced colitis than the exosomes of other macrophage phenotypes and macrophage cells.

\section{M2b Macrophage Exosomes Alleviate Colon Damage in Mice With DSS-Induced Colitis}

The results of histological assessment showed that DSS induced a significant inflammatory response, including inflammatory cell infiltration, crypt loss, sub-mucosal edema, crypt abscess formation, goblet cell loss, and reactive epithelial hyperplasia (Figure 4A). The results of H\&E histopathology indicated that mice with colitis that were treated with M2b macrophage exosomes had significantly reduced inflammatory responses, compared with those treated with the exosomes of other macrophage phenotypes and macrophage cells (Figure 4A). Consistent with the histological assessment, histopathological 

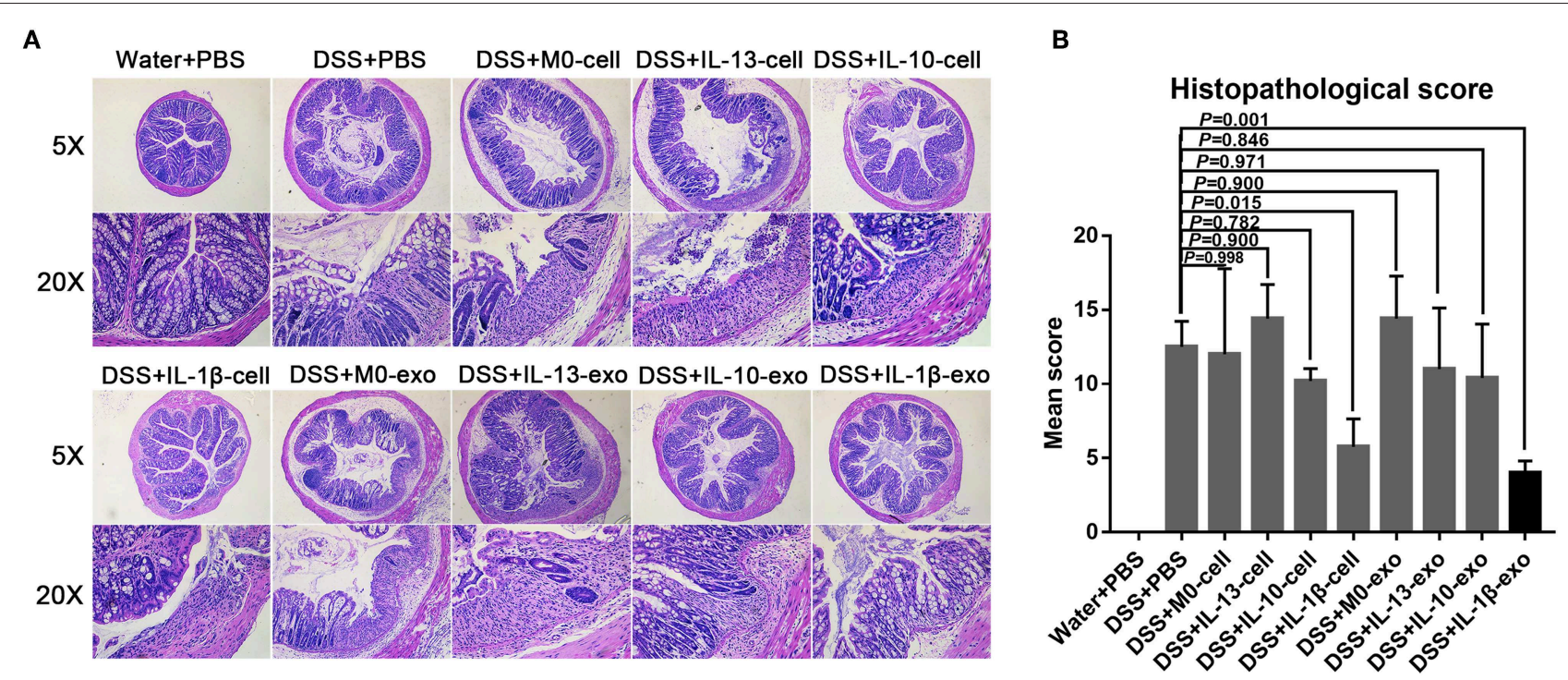

FIGURE 4 | Histopathological changes in the colons of mice treated with macrophage exosomes. (A) Colon sections were examined with hematoxylin and eosin (H \& E) $(5 \times$ and $20 \times)$. (B) Histopathological scores were determined in a blinded fashion.

scores, determined in a blinded fashion, in the colons of the groups treated with $\mathrm{M} 2 \mathrm{~b}$ macrophage exosomes were significantly lower than those in the colons of groups treated with the exosomes of other macrophage phenotypes and macrophage cells (Figure 4B, Table 5). Taken together, these data indicate that M2b macrophage exosomes could alleviate colon damage in mice with DSS-induced colitis, and their effects are superior to those of the exosomes of other macrophage phenotypes and macrophage cells.

\section{M2b Macrophage Exosomes Increased Treg Percentages in Mice With DSS-Induced Colitis}

The Treg subsets play an important role in regulating immune homeostasis and tolerance. In IBD, Treg subsets are linked to the development of inflammatory disorders. To determine the Treg subset levels, cells were isolated from the spleens of mice, and stained with fluorochrome-conjugated antibodies against CD3e, CD4, CD25, and Foxp3. The changes in Treg subset levels were evaluated by flow cytometry. We noted that the percentages of $\mathrm{CD} 3 \mathrm{e}^{+} \mathrm{CD} 4{ }^{+} \mathrm{CD} 25^{+}$Foxp $3^{+}$cells in the spleens of mice with DSS-induced colitis that were treated with M2b macrophage exosomes were significantly increased $(12.7 \pm 0.7 \%$; $P<0.05)$, compared with those in the spleens of PBS-treated mice with DSS-induced colitis $(9.3 \pm 1 \%)$ (Figure 5, Table 5). In addition, the percentages of $\mathrm{CD} 3 \mathrm{e}^{+} \mathrm{CD} 4{ }^{+} \mathrm{CD} 25^{+}$Foxp $3^{+}$cells in the spleens of mice with DSS-induced colitis that were treated with M2c macrophage exosomes were significantly increased (13.5 $\pm 3 \% ; P<0.001)$ compared with PBS-treated mice with DSS-induced colitis (9.3 $\pm 1 \%$ ) (Figure 5, Table 5). These findings indicate that $\mathrm{M} 2 \mathrm{~b}$ and $\mathrm{M} 2 \mathrm{c}$ macrophage exosomes had protective effects against DSS-induced colitis mediated by an increased number of Treg cells.

\section{M2b Macrophage Exosomes Regulate Inflammatory Cytokine Production in Mice With DSS-Induced Colitis}

In IBD, levels of the pro-inflammatory cytokines, IL-1 $\beta$, IL-6, and IL-17A are predictably increased in the mucosa. To determine whether macrophage exosomes can regulate IL-1 $\beta$, IL-6, and IL-17A production in mice with DSS-induced colitis, real-time PCR was used to examine the expression of IL-1 $\beta$, IL-6, and IL17A. In the DSS + PBS group, IL-1 $\beta$, IL-6, and IL-17A showed high levels of expression (Figure 6). Compared with the DSS + PBS group, IL-1 $\beta$, IL-6, and IL-17A expression levels were reduced, following treatment with $\mathrm{M} 2 \mathrm{~b}$ macrophage exosomes (Figure 6). In addition, the expression levels of IL-1 $\beta$, IL-6, and IL-17A in the groups treated with M2b macrophage exosomes were lower than those in groups treated with the exosomes of other macrophage phenotypes and macrophage cells (Figure 6). These results indicate that $\mathrm{M} 2 \mathrm{~b}$ macrophage exosomes can regulate inflammatory cytokine production in mice with DSSinduced colitis.

\section{M2b Macrophage Exosomes Carrying CCL1 Interact With CCR8 to Regulate} Immunity in Mice With DSS-Induced Colitis

The M2b macrophages are characterized specifically by the secretion of the CCL1 chemokine. Furthermore, CCL1 can interact with CCR8, which is expressed on Th2 cells and Treg cells for immune regulation. Therefore, we questioned whether M2b macrophage exosomes carrying the CCL1 protein to the colon, interact with the CCR8 receptor to regulate Th2 polarization and Treg cells, and thereby attenuate DSSinduced colitis. As expected, ex vivo fluorescence imaging showed that macrophage exosomes arrived the colon of mice 
A
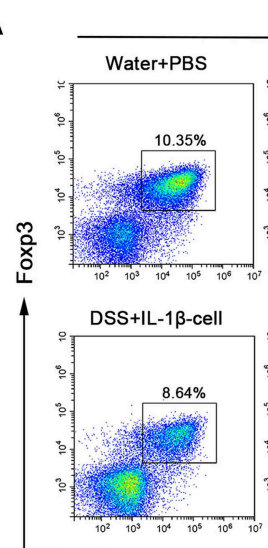
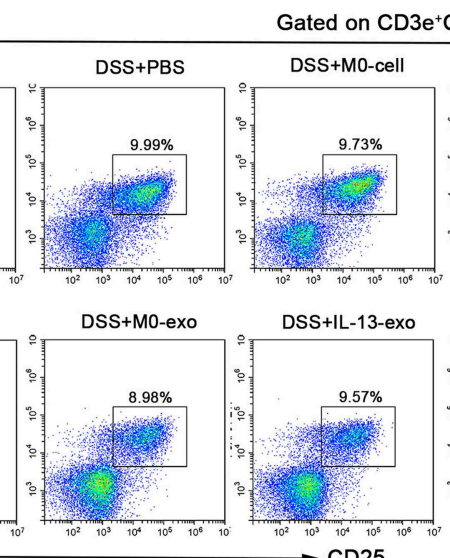
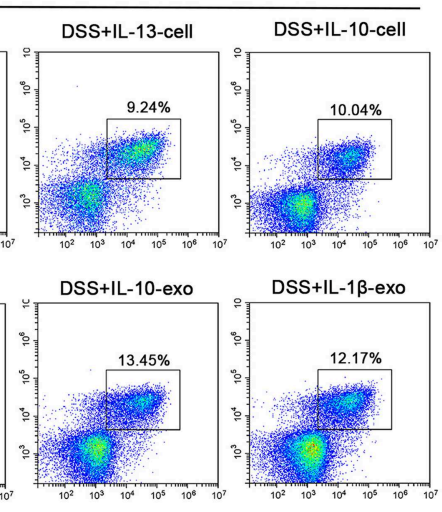

CD25

FIGURE 5 | Splenic Treg subset levels in mice with experimental colitis. (A) Cells were isolated from the spleens of mice and stained with fluorochrome-conjugated antibodies against CD3e, CD4, CD25, and Foxp3. The number of Tregs in the spleens were expressed as percentages of the CD3e ${ }^{+}$CD4 ${ }^{+}$CD25 ${ }^{+}$Foxp3 ${ }^{+}$cell population. (B) Statistical analysis of Tregs.
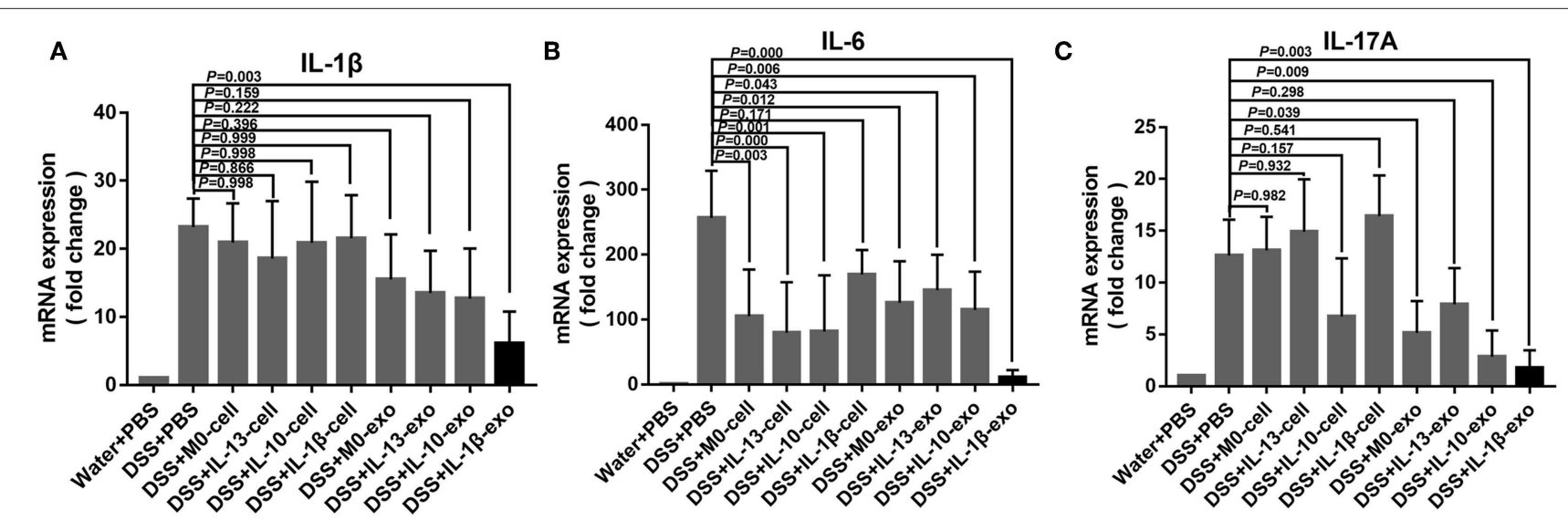

FIGURE 6 | Inflammatory cytokine expression in the colons of mice was determined by real-time PCR; the housekeeping gene, GAPDH, was used as an internal reference. (A) The $I L-1 \beta$ mRNA expression levels. (B) The $I L-6$ mRNA expression levels. (C) The $I L-17 A$ mRNA expression levels.

(Figure 7A). In addition, expression of the CCL1 protein in the exosomes was analyzed by western blotting. The CCL1 protein expression in M2b macrophage exosomes was significantly higher than that in other exosomes (Figure 7B). Real-time PCR demonstrated higher expression of CCL1 and CCR8 in the colon, following treatment with $\mathrm{M} 2 \mathrm{~b}$ macrophage exosomes (Figure 8A). The expression of IL-4, which was mainly produced by Th2 cells, was also increased following treatment with M2b macrophage exosomes (Figure 8A). The CCL1, CCR8, and IL4 protein expression levels were confirmed by western blotting, and the results were consistent with those of real-time PCR (Figure 8B). Furthermore, the protein expression levels of CCL1, CCR8, and IL-4 were detected by immunohistochemistry, and found to be significantly increased following treatment with $\mathrm{M} 2 \mathrm{~b}$ macrophage exosomes, compared with the PBS treatment (Figure 8C).

Taken together, these data indicate that M2b macrophage exosomes carrying the CCL1 protein to the colon interact with CCR8 to promote IL-4 expression (Th2 polarization) and increase Treg percentages (Figure 5). The Th2-type immune response balanced the Th1-type immune response induced by DSS administration, and Treg cells balanced the inflammatory disorders of DSS-induced colitis, thereby relieving the colitis.

\section{DISCUSSION}

In this study, we assessed whether exosomes derived from different types of M2 macrophage phenotypes could have protective effects against the development of DSS-induced colitis. As expected, the current data demonstrate that body weight loss and the DAI are both reduced after treatment with M2a, M2b, and M2c macrophage exosomes. Moreover, after treatment with M2 macrophage exosomes, the colon length was improved in mice with colitis, and the mean macroscopic scores in the colon were decreased. Furthermore, M2b macrophage exosomes were more effective than M2a and M2c macrophage 

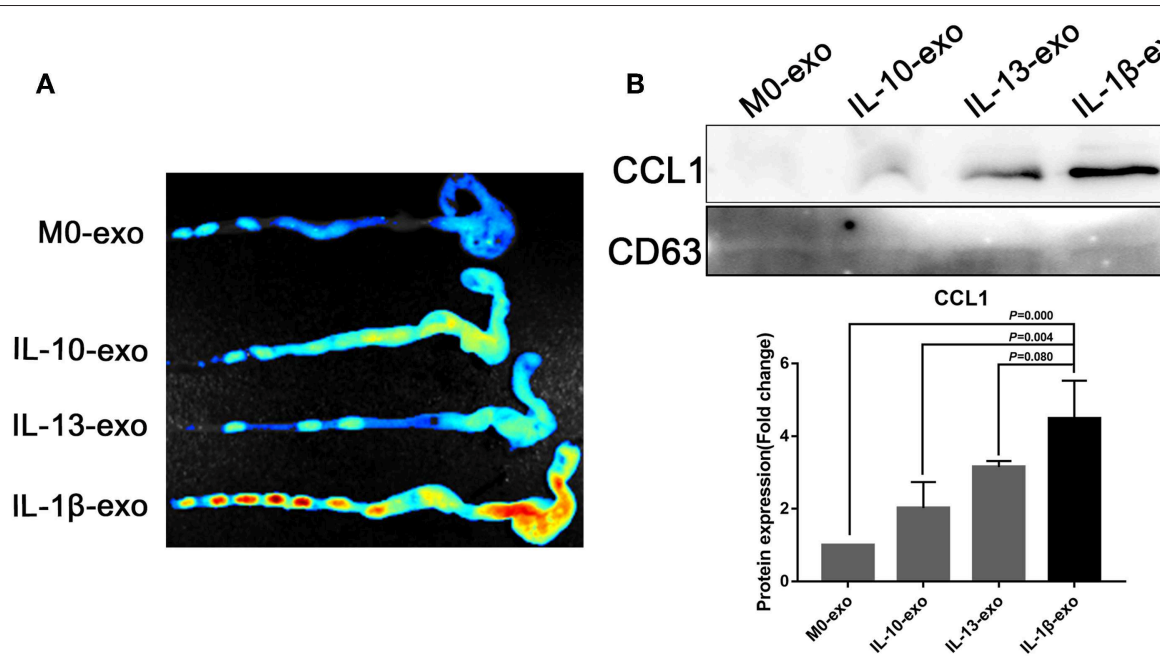

FIGURE 7 | Ex vivo fluorescence imaging of exosomes in the colon; the CCL1 protein in exosomes was detected by western blotting. (A) Ex vivo fluorescence imaging of the distribution of DiR labeled exosomes in the colon. (B) Western blotting analysis of CCL1 protein expression in exosomes purified from various macrophage phenotypes, exosome marker CD63 used as internal reference.

exosomes. Histological examination and scores showed that M2b macrophage exosomes alleviated colon damage in mice with DSS-induced colitis. In addition, M2b macrophage exosomes increased the percentage of Treg cells in mice with DSS-induced colitis and reduced pro-inflammatory cytokine (IL-1 $\beta$, IL-6, and IL-17A) production in the colon of mice with DSS-induced colitis. Additionally, we found that M2b macrophage exosomes, carrying the CCL1 protein to the colon, interact with CCR8 to promote Th2 polarization and increase Treg percentages, thereby relieving colitis.

Innate immune responses are mediated by a variety of cell types, including neutrophils, monocytes, macrophages, dendritic cells, and epithelial, endothelial, and mesenchymal cells as the first line of defense (25). The infiltration of the gut mucosa and epithelium by polymorphonuclear leukocytes constitute the earliest signs of intestinal inflammation, and this infiltration persists throughout the course of IBD (26). In addition to innate immunity, another important factor affecting IBD is an imbalance in adaptive immunity. Effector $\mathrm{T}$ cells, including Th1, Th2, and Th17, have plasticity and can quickly adapt to stimulation by the surrounding environment, which is closely associated with the pathogenesis of IBD (27). The Treg cells are essential for the development of tolerance to self- and non-self-antigens (28). Given the importance of Treg cells in innate and adaptive immunity, defects in their functions underlie autoimmune, infectious, and chronic inflammatory conditions, including IBD (29). Moreover, imbalances in natural killer (NK) cells, natural killer $\mathrm{T}$ (NKT) cells, and innate lymphocytes (ILC) in the intestinal mucosa can also be important factors in the pathogenesis of IBD. Therefore, anti-inflammatory and immunoregulatory activities are key targets for the treatment of IBD.

Exosomes transport proteins, nucleic acids, and lipids in vitro and in vivo (30). Exosomes also have important biological functions in the immune response, inflammation, tumor growth, and infection (31). They also have less biohazardous potential, less cytotoxicity, and are not easily degraded. Therefore, exosomes have potential applications in the diagnosis, treatment, and prognosis of conditions like IBD. Previous studies have demonstrated that exosomes derived from human umbilical cord mesenchymal stem cells have profound effects in alleviating DSS-induced IBD. The exosomes may exert these effects by regulating the level of ubiquitin modification and modulating IL-7 expression in macrophages (20, 32). Extracellular vesicles secreted by hookworms can interact with host cells and attenuate the severity of 2,4,6trinitrobenzenesulfonic acid (TNBS)-induced colitis in mice (33). Furthermore, exosomes released by interleukin-10-treated dendritic cells can inhibit TNBS-induced colitis in rats (34). The functions of exosomes in IBD primarily depend on the internal functional components and exosome-induced transport mechanisms involving cell-cell communications or cell-environment interactions. Designing new drugs by exosomelike-structure may provide a new insight into IBD treatment (35). Like exosomes, other studies also supply novel insights into potential IBD treatment, such as purified fruit bromelain, which can inhibit epithelial TNF- $\alpha$ receptors to ameliorate intestinal inflammation and barrier dysfunction in colitis (36). As well as that, fortunellin induced modulation of phosphatase and tensin homolog by miR-374a maintains intestinal barrier functions and decreases inflammation in TNBS-induced rat colitis (37). However, more animal and clinical research is needed to study the functions of novel insights (including exosomes) on IBD.

Macrophages are commonly classified as M1 macrophages and M2 macrophages. Previous studies have shown that macrophage exosomes affect disease processes. Exosomes released by differentially activated macrophages influence the 
A
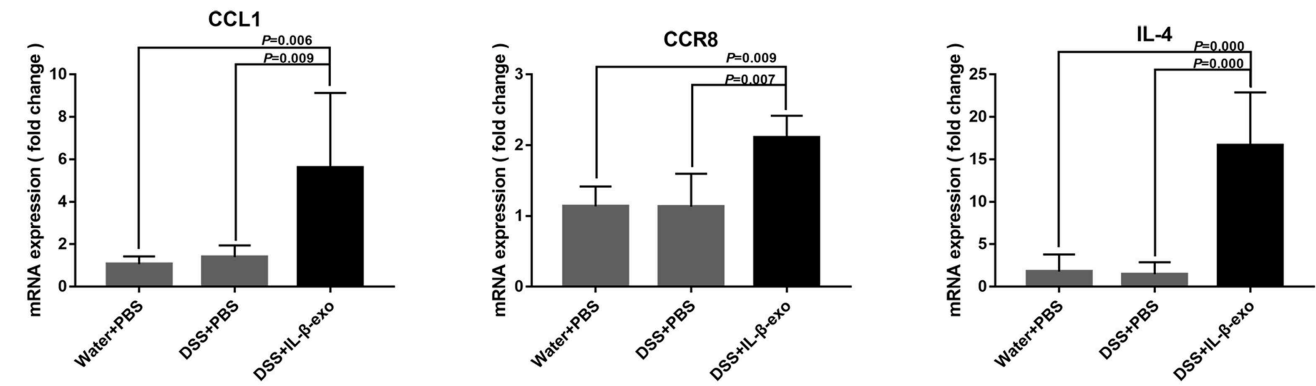

B
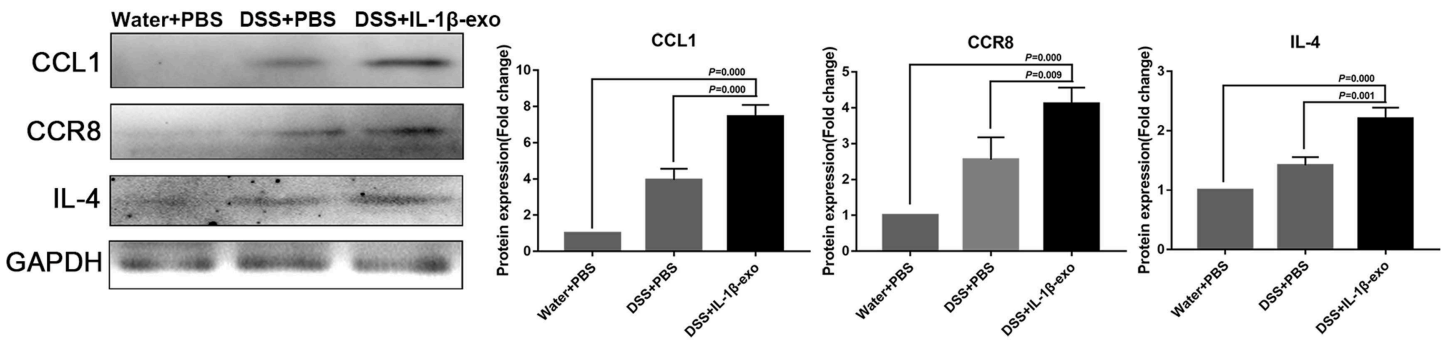

C
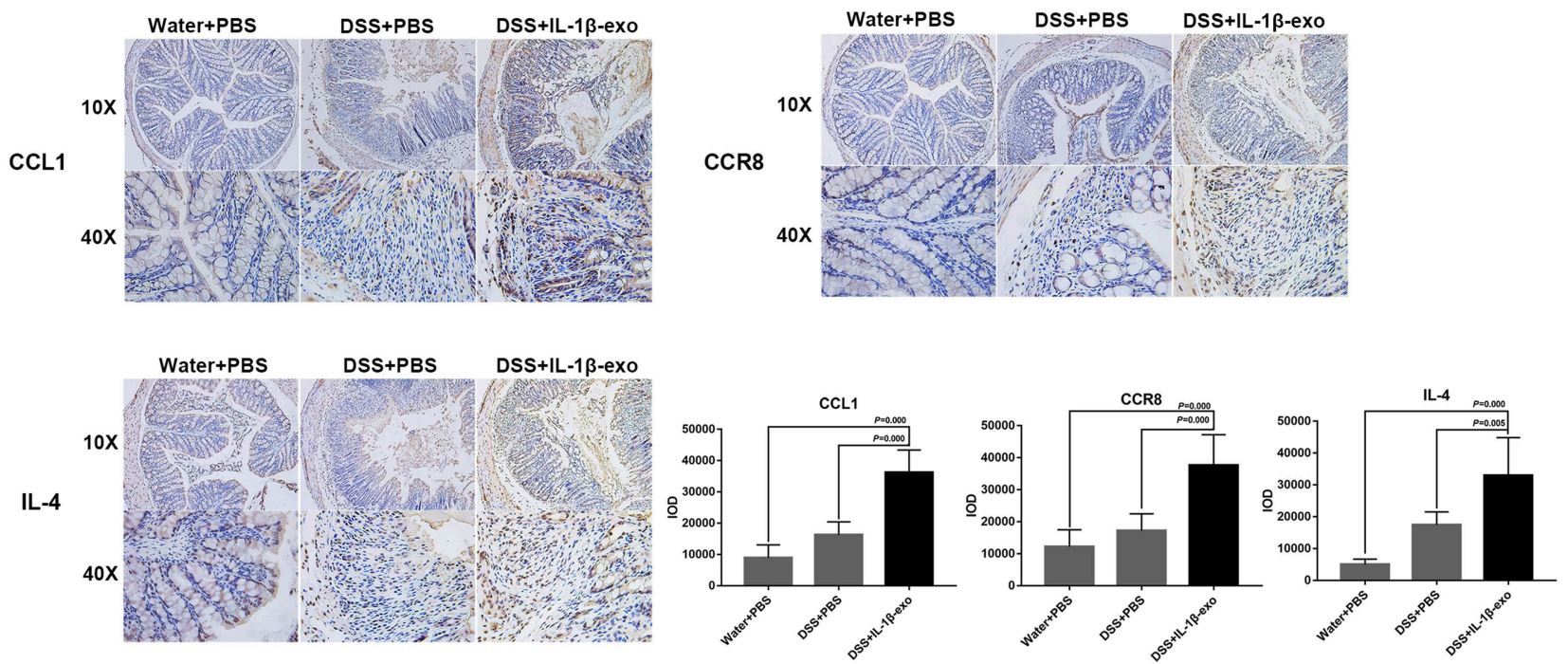

FIGURE 8 | CCL1, CCR8, and IL4 expression in the colons of mice treated with M2b macrophage exosomes. (A) The CCL1, CCR8, and IL4 mRNA expression levels in the colons of mice were determined by real-time PCR; the housekeeping gene, GAPDH, was used as an internal reference. (B) Western blotting analysis of CCL1, CCR8, and IL4 protein expression in the colons of mice. (C) CCL1, CCR8, and IL4 expression in colon tissue was detected by immunohistochemistry, and the sum of the integrated optical density (IOD) was analyzed.

dormancy and resurgence of breast cancer cells in the bone marrow stroma (38). In colon cancer, the M2 macrophages secrete exosomes that promote cell migration and invasion (39). Exosomes derived from tumor-associated macrophages promote the migration of gastric cancer cells via the transfer of functional apolipoprotein E (40). However, to the best of our knowledge, the role of macrophage exosomes in IBD has not yet been reported. Based on the roles of M2 macrophages in anti-inflammatory and immunoregulatory activity, we studied the combined advantages of exosomes derived from various M2 macrophage phenotypes in IBD. We found that the M2b macrophage exosomes effectively attenuated DSS-induced colitis.

The Treg cells are key regulators of immune homeostasis (41). They are important for the control of the immune response, and they alleviate defects during the development of autoimmune and chronic inflammatory conditions, such as IBD (29). The Treg cells also contribute to the complex pathogenesis of IBD during the onset and development of the disease, and patients with IBD have significantly reduced numbers of peripheral Treg cells $(42,43)$. Our results have shown that the percentage of Treg cells 
in the spleens of mice with DSS-induced colitis were increased following treatment with $\mathrm{M} 2 \mathrm{~b}$ macrophage exosomes. These results indicate that $\mathrm{M} 2 \mathrm{~b}$ macrophage exosomes had protective effects during the development of DSS-induced colitis, which were partly mediated by the up-regulation of Treg cells.

Studies have shown that levels of the pro-inflammatory cytokines, IL-1 $\beta$ and IL-6, are predictably increased in the mucosa of patients with Crohn's disease and ulcerative colitis (44). Mucosal immune cells are an abundant source of IL-1 $\beta$ (44). Furthermore, IL-6 is abundantly secreted in the intestinal mucosa of patients with IBD, and is implicated in the pathogenesis of IBD via the soluble IL-6 receptor, activation of immune cells, inhibition of apoptosis, and induction of Th17-cell differentiation (45). The expression of IL-17 is increased in the serum and mucosa of most patients with IBD, and is consistently higher in Crohn's disease than it is in ulcerative colitis (46). Our results showed that IL-1 $\beta$, IL-6, and IL-17A were all down-regulated in mice with DSS-induced colitis, following treatment with M2b macrophage exosomes.

The M2b macrophages play a role in Th2 activation and immunoregulation $(12,14)$. The $\mathrm{M} 2 \mathrm{~b}$ macrophages are also specifically characterized by secretion of the CCL1 chemokine (47), a ligand of the cognate chemokine receptor CCR8 (48, 49). The CCR8 receptor is expressed at high levels in Treg cells and in polarized Th2 cells, both of which migrate in response to the appropriate agonist, CCL1 (50). Accordingly, CCR8 knockout mice show impaired Th2 cytokine production, and the CCL1/CCR8 axis has been implicated in the cutaneous homing of T cells $(51,52)$. Studies have shown that CCL1 and its receptor, CCR8, mediate the conversion of mesenchymal stem cells to embryoid bodies expressing Treg cells (53), and disruption of the CCL1-CCR8 axis inhibits vascular Treg recruitment and functions (54). In the present study, we found that $\mathrm{M} 2 \mathrm{~b}$ macrophage exosomes carrying the CCL1 protein to the colon interact with CCR8 to promote IL-4 expression (Th2 polarization) and increase Treg percentages. As an antiinflammatory cytokine, IL-4 inhibited inflammation in IBD patients (55) and induced a Th2-type immune response in the mice with colitis. These effects, induced by IL-4, can balance the Th1-type immune response and thereby relieve colitis (56). In addition, M2b macrophage exosomes increased Treg percentages

\section{REFERENCES}

1. Di Sabatino A, Lenti MV, Giuffrida P, Vanoli A, Corazza GR. New insights into immune mechanisms underlying autoimmune diseases of the gastrointestinal tract. Autoimmun Rev. (2015) 14:1161-9. doi: 10.1016/j.autrev.2015.08.004

2. Ng SC, Shi HY, Hamidi N, Underwood FE, Tang W, Benchimol EI, et al. Worldwide incidence and prevalence of inflammatory bowel disease in the 21st century: a systematic review of population-based studies. Lancet. (2018) 390:2769-78. doi: 10.1016/S0140-6736(17)32448-0

3. Hanauer SB. Inflammatory bowel disease: epidemiology, pathogenesis, and therapeutic opportunities. Inflamm Bowel Dis. (2006) 12 (Suppl 1):S39. doi: 10.1097/01.MIB.0000195385.19268.68

4. Maloy KJ, Powrie F. Intestinal homeostasis and its breakdown in inflammatory bowel disease. Nature. (2011) 474:298306. doi: 10.1038/nature10208 via the CCL1/CCR8 axis, which can further balance the effects of inflammatory disorders.

In summary, our findings show that $\mathrm{M} 2 \mathrm{~b}$ macrophage exosomes attenuate disease activity, up-regulate Treg cells and IL-4, and reduce pro-inflammatory cytokine (IL-1 $\beta$, IL-6, and IL17A) production in mice with DSS-induced colitis. The results also suggest that M2b macrophage exosomes exert protective effects in DSS-induced colitis, which are mainly mediated by the CCL1/CCR8 axis. Taken together, our findings provide insight into the immunobiology of M2b macrophage exosomes and suggest a useful novel approach to IBD treatment.

\section{DATA AVAILABILITY STATEMENT}

All datasets generated for this study are included in the manuscript/supplementary files.

\section{ETHICS STATEMENT}

The animal study was reviewed and approved by The Animal Research Ethics Committee of Sun Yat-sen University.

\section{AUTHOR CONTRIBUTIONS}

RY, LW, XS, PH, DY, and ZW drafted this manuscript. YL and RY performed the experiments, analyses, and interpretation of the data. YH helped the aforementioned authors to develop the experiments. DY and ZW provided final approval of the version to be published. All authors discussed the complete dataset to establish an integral and coherent analysis.

\section{FUNDING}

The study was supported by China Postdoctoral Science Foundation (No. 2018M640858), National Natural Science Foundation of China (No. 81572014, 81871682, 81860330, and 81860365), Pearl River Nova Program of Guangzhou (Grant No. 201710010030), Youth teacher training program of Sun Yat-sen University (17ykpy09), and the Major Project Cultivation Plan of Xizang Minzu University (18MDZ02).
5. Maloy KJ, Powrie F. Immunopathogenesis of IBD: current state of the art. Nat Rev Gastroenterol Hepatol. (2016) 13:13-27. doi: 10.1038/nrgastro.20 15.186

6. Gracie DJ, Ford AC. IBS-like symptoms in patients with ulcerative colitis. Clin Exp Gastroenterol. (2015) 8:101-9. doi: 10.2147/CEG.S58153

7. Boldeanu MV, Siloşi I, Ghiluşi M, Cojocaru M, Biciuşcă V, Avrămescu CS, et al. Investigation of inflammatory activity in ulcerative colitis. Roman J Morphol Embryol. (2014) 55:1345-51.

8. Danese S, Fiorino G, Peyrin-Biroulet L, Lucenteforte E, Virgili G, Moja L, et al. Biological agents for moderately to severely active ulcerative colitis: a systematic review and network meta-analysis. Ann Int Med. (2014) 160:70411. doi: 10.7326/M13-2403

9. Hazlewood GS, Rezaie A, Borman M, Panaccione R, Ghosh S, Seow $\mathrm{CH}$, et al. Comparative effectiveness of immunosuppressants and biologics for inducing and maintaining remission in Crohn's disease: 
a network meta-analysis. Gastroenterology. (2015) 148:344-54.e5; quiz e14-5. doi: 10.1053/j.gastro.2014.10.011

10. Paramsothy S, Cleveland NK, Zmeter N, Rubin DT. The role of biosimilars in inflammatory Bowel disease. Gastroenterol Hepatol. (2016) 12:741-51.

11. Arora S, Dev K, Agarwal B, Das P, Syed MA. Macrophages: their role, activation and polarization in pulmonary diseases. Immunobiology. (2018) 223:383-96. doi: 10.1016/j.imbio.2017.11.001

12. Shapouri-Moghaddam A, Mohammadian S, Vazini H, Taghadosi M, Esmaeili SA, Mardani F, et al. Macrophage plasticity, polarization, and function in health and disease. J Cell Physiol. (2018) 233:6425-40. doi: 10.1002/jcp.26429

13. Murray PJ, Wynn TA. Obstacles and opportunities for understanding macrophage polarization. J Leukoc Biol. (2011) 89:557-63. doi: 10.1189/jlb.0710409

14. Chistiakov DA, Bobryshev YV, Nikiforov NG, Elizova NV, Sobenin IA, Orekhov AN. Macrophage phenotypic plasticity in atherosclerosis: the associated features and the peculiarities of the expression of inflammatory genes. Int J Cardiol. (2015) 184:436-45. doi: 10.1016/j.ijcard.2015.03.055

15. Wang $\mathrm{N}$, Liang $\mathrm{H}$, Zen $\mathrm{K}$. Molecular mechanisms that influence the macrophage m1-m2 polarization balance. Front Immunol. (2014) 5:614. doi: 10.3389/fimmu.2014.00614

16. Martinez FO, Sica A, Mantovani A, Locati M. Macrophage activation and polarization. Front Biosci. (2008) 13:453-61. doi: 10.2741/2692

17. Zizzo G, Hilliard BA, Monestier M, Cohen PL. Efficient clearance of early apoptotic cells by human macrophages requires M2c polarization and MerTK induction. J Immunol. (2012) 189:3508-20. doi: 10.4049/jimmunol.1200662

18. Boyiadzis $\mathrm{M}$, Whiteside $\mathrm{T}$. The emerging roles of tumor-derived exosomes in hematological malignancies. Leukemia. (2017) 31:1259. doi: 10.1038/leu.2017.91

19. Wang L, Yu Z, Wan S, Wu F, Chen W, Zhang B, et al. Exosomes derived from dendritic cells treated with Schistosoma japonicum soluble egg antigen attenuate DSS-induced colitis. Front Pharmacol. (2017) 8:651. doi: 10.3389/fphar.2017.00651

20. Mao F, Wu Y, Tang X, Kang J, Zhang B, Yan Y, et al. Exosomes derived from human umbilical cord mesenchymal stem cells relieve inflammatory Bowel disease in mice. BioMed Res Int. (2017) 2017:5356760. doi: 10.1155/2017/5356760

21. Wang Y, Tian J, Tang X, Rui K, Tian X, Ma J, et al. Exosomes released by granulocytic myeloid-derived suppressor cells attenuate DSS-induced colitis in mice. Oncotarget. (2016) 7:15356-68. doi: 10.18632/oncotarget.7324

22. Marcus ME, Leonard JN. FedExosomes: engineering therapeutic biological nanoparticles that truly deliver. Pharmaceuticals. (2013) 6:659-80. doi: 10.3390/ph6050659

23. Sann H, von Erichsen J, Hessmann M, Pahl A, Hoffmeyer A. Efficacy of drugs used in the treatment of IBD and combinations thereof in acute DSS-induced colitis in mice. Life Sci. (2013) 92:708-18. doi: 10.1016/j.lfs.2013.01.028

24. Yang Y, Yan H, Jing M, Zhang Z, Zhang G, Sun Y, et al. Andrographolide derivative AL-1 ameliorates TNBS-induced colitis in mice: involvement of NF- $\kappa \mathrm{B}$ and PPAR- $\gamma$ signaling pathways. Sci Rep. (2016) 6:29716. doi: 10.1038/srep29716

25. de Souza HSP, Fiocchi C, Iliopoulos D. The IBD interactome: an integrated view of aetiology, pathogenesis and therapy. Nat Rev Gastroenterol Hepatol. (2017) 14:739-49. doi: 10.1038/nrgastro.2017.110

26. Brazil JC, Louis NA, Parkos CA. The role of polymorphonuclear leukocyte trafficking in the perpetuation of inflammation during inflammatory bowel disease. Inflamm Bowel Dis. (2013) 19:1556-65. doi: 10.1097/MIB.0b013e318281f54e

27. Murphy KM, Stockinger B. Effector $\mathrm{T}$ cell plasticity: flexibility in the face of changing circumstances. Nat Immunol. (2010) 11:674-80. doi: $10.1038 /$ ni.1899

28. Harrison OJ, Powrie FM. Regulatory $\mathrm{T}$ cells and immune tolerance in the intestine. Cold Spring Harb Perspect Biol. (2013) 5:a18341. doi: 10.1101/cshperspect.a018341

29. Mayne CG, Williams CB. Induced and natural regulatory $T$ cells in the development of inflammatory bowel disease. Inflamm Bowel Dis. (2013) 19:1772. doi: 10.1097/MIB.0b013e318281f5a3

30. Kourembanas S. Exosomes: vehicles of intercellular signaling, biomarkers, and vectors of cell therapy. Annu Rev Physiol. (2015) 77:13-27. doi: 10.1146/annurev-physiol-021014-071641
31. Barile L, Vassalli G. Exosomes: therapy delivery tools and biomarkers of diseases. Pharmacol Ther. (2017) 174:6378. doi: 10.1016/j.pharmthera.2017.02.020

32. Wu Y, Qiu W, Xu X, Kang J, Wang J, Wen Y, et al. Exosomes derived from human umbilical cord mesenchymal stem cells alleviate inflammatory bowel disease in mice through ubiquitination. Am J Transl Res. (2018) 10:2026-36.

33. Eichenberger RM, Ryan S, Jones L, Buitrago G, Polster R, Montes de Oca $\mathrm{M}$, et al. Hookworm secreted extracellular vesicles interact with host cells and prevent inducible colitis in mice. Front Immunol. (2018) 9:850. doi: $10.3389 /$ fimmu.2018.00850

34. Yang $\mathrm{X}$, Meng $\mathrm{S}$, Jiang $\mathrm{H}$, Chen $\mathrm{T}, \mathrm{Wu} \mathrm{W}$. Exosomes derived from interleukin-10-treated dendritic cells can inhibit trinitrobenzene sulfonic acid-induced rat colitis. Scand J Gastroenterol. (2010) 45:1168-77. doi: 10.3109/00365521.2010.490596

35. Zhang H, Wang L, Li C, Yu Y, Yi Y, Wang J, et al. Exosomeinduced regulation in inflammatory bowel disease. Front Immunol. (2019)10:1464. doi: 10.3389/fimmu.2019.01464

36. Zhou Z, Wang L, Feng P, Yin L, Wang C, Zhi S, et al. Inhibition of epithelial TNF- $\alpha$ receptors by purified fruit bromelain ameliorates intestinal inflammation and barrier dysfunction in colitis. Front Immunol. (2017) 8:1468. doi: 10.3389/fimmu.2017.01468

37. Xiong Y, Qiu J, Li C, Qiu Y, Guo L, Liu Y, et al. Fortunellin-induced modulation of phosphatase and tensin homolog by microrna-374a decreases inflammation and maintains intestinal barrier function in colitis. Front Immunol. (2018) 9:83. doi: 10.3389/fimmu.2018.00083

38. Walker ND, Elias M, Guiro K, Bhatia R, Greco SJ, Bryan M, et al. Exosomes from differentially activated macrophages influence dormancy or resurgence of breast cancer cells within bone marrow stroma. Cell Death Dis. (2019) 10:59. doi: 10.1038/s41419-019-1304-z

39. Lan J, Sun L, Xu F, Liu L, Hu F, Song D, et al. M2 Macrophage-derived exosomes promote cell migration and invasion in colon cancer. Cancer Res. (2019) 79:146-58. doi: 10.1158/0008-5472.CAN-18-0014

40. Zheng P, Luo Q, Wang W, Li J, Wang T, Wang P, et al. Tumor-associated macrophages-derived exosomes promote the migration of gastric cancer cells by transfer of functional Apolipoprotein E. Cell Death Dis. (2018) 9:434. doi: 10.1038/s41419-018-0465-5

41. Sakaguchi S, Yamaguchi T, Nomura T, Ono M. Regulatory T cells and immune tolerance. Cell. (2008) 133:775-87. doi: 10.1016/j.cell.2008.05.009

42. Niederau C, Backmerhoff F, Schumacher B. Inflammatory mediators and acute phase proteins in patients with Crohn's disease and ulcerative colitis. Hepatogastroenterology. (1997) 44:90-107.

43. Nielsen OH, Ciardelli T, Wu Z, Langholz E, Kirman I. Circulating soluble interleukin-2 receptor $\alpha$ and $\beta$ chain in inflammatory bowel disease. $A m J$ Gastroenterol. (1995) 90:1301-6.

44. Youngman KR, Simon PL, West GA, Cominelli F, Rachmilewitz D, Klein JS, et al. Localization of intestinal interleukin 1 activity and protein and gene expression to lamina propria cells. Gastroenterology. (1993) 104:74958. doi: 10.1016/0016-5085(93)91010-F

45. Mudter J, Neurath MF. Apoptosis of $\mathrm{T}$ cells and the control of inflammatory bowel disease: therapeutic implications. Gut. (2007) 56:293303. doi: 10.1136/gut.2005.090464

46. Fujino S, Andoh A, Bamba S, Ogawa A, Hata K, Araki Y, et al. Increased expression of interleukin 17 in inflammatory bowel disease. Gut. (2003) 52:65-70. doi: 10.1136/gut.52.1.65

47. Bianchini R, Roth-Walter F, Ohradanova-Repic A, Flicker S, Hufnagl K, Fischer MB, et al. IgG4 drives M2a macrophages to a regulatory M2blike phenotype: potential implication in immune tolerance. Allergy. (2019) 74:483-94. doi: 10.1111/all.13635

48. Asai A, Nakamura K, Kobayashi M, Herndon DN, Suzuki F. CCL1 released from $\mathrm{M} 2 \mathrm{~b}$ macrophages is essentially required for the maintenance of their properties. J Leukoc Biol. (2012) 92:859-67. doi: 10.1189/jlb.0212107

49. Asai A, Tsuchimoto Y, Ohama H, Fukunishi S, Tsuda Y, Kobayashi M, et al. Host antitumor resistance improved by the macrophage polarization in a chimera model of patients with HCC. Oncoimmunology. (2017) 6:e1299301. doi: 10.1080/2162402X.2017.1299301

50. Sironi M, Martinez FO, D'Ambrosio D, Gattorno M, Polentarutti N, Locati $\mathrm{M}$, et al. Differential regulation of chemokine production by Fc $\gamma$ receptor engagement in human monocytes: association of CCL1 with a distinct form 
of M2 monocyte activation (M2b, Type 2). J Leukoc Biol. (2006) 80:3429. doi: 10.1189/jlb.1005586

51. Schaerli P, Ebert L, Willimann K, Blaser A, Roos RS, Loetscher P, et al. A skinselective homing mechanism for human immune surveillance T cells. J Exp Med. (2004) 199:1265-75. doi: 10.1084/jem.20032177

52. Chensue SW, Lukacs NW, Yang T-Y, Shang X, Frait KA, Kunkel SL, et al. Aberrant in vivo $\mathrm{T}$ helper type 2 cell response and impaired eosinophil recruitment in CC chemokine receptor 8 knockout mice. J Exp Med. (2001) 193:573-84. doi: 10.1084/jem.193.5.573

53. Haque NS, Tuteja A, Haque N. CC chemokine CCL1 receptor CCR8 mediates conversion of mesenchymal stem cells to embryoid bodies expressing FOXP3+ CCR8+ regulatory T cells. PLoS ONE. (2019) 14:e0218944. doi: 10.1371/journal.pone.0218944

54. Vila-Caballer M, González-Granado JM, Zorita V, Nabah YNA, Silvestre-Roig C, del Monte-Monge A, et al. Disruption of the CCL1-CCR8 axis inhibits vascular Treg recruitment and function and promotes atherosclerosis in mice. J Mol Cell Cardiol. (2019) 132:154-63. doi: 10.1016/j.yjmcc.2019.05.009

55. Fan H, Du J, Liu X, Zheng W, Zhuang Z, Wang C, et al. Effects of pentasacombined probiotics on the microflora structure and prognosis of patients with inflammatory bowel disease. Turk J Gastroenterol. (2019) 30:6805. doi: 10.5152/tjg.2019.18426

56. Xu J, Liu M, Yu P, Wu L, Lu Y. Effect of recombinant Trichinella spiralis cysteine proteinase inhibitor on TNBS-induced experimental inflammatory bowel disease in mice. Int Immunopharmacol. (2019) 66:2840. doi: 10.1016/j.intimp.2018.10.043

Conflict of Interest: The authors declare that the research was conducted in the absence of any commercial or financial relationships that could be construed as a potential conflict of interest.

Copyright (c) 2019 Yang, Liao, Wang, He, Hu, Yuan, Wu and Sun. This is an open-access article distributed under the terms of the Creative Commons Attribution License (CC BY). The use, distribution or reproduction in other forums is permitted, provided the original author(s) and the copyright owner(s) are credited and that the original publication in this journal is cited, in accordance with accepted academic practice. No use, distribution or reproduction is permitted which does not comply with these terms. 